\title{
Communication \\ Upconversion Luminescent Humidity Sensors Based on Lanthanide-Doped MOFs
}

\author{
Zhuo Wang ${ }^{1,2}\left(\mathbb{D}\right.$, Guotao Sun ${ }^{3}$, Jiabo Chen ${ }^{2}$, Yao Xie ${ }^{4}$, Hong Jiang ${ }^{1}$ and Lining Sun $2,3,4, * \mathbb{C}$ \\ 1 State Key Laboratory of Marine Resource Utilization in South China Sea \& Special Glass Key Lab of Hainan \\ Province, School of Information and Communication Engineering, Hainan University, Haikou 570228, China; \\ wangzhuosust@163.com (Z.W.); jhong63908889@sina.com (H.J.) \\ 2 Department of Chemistry, College of Sciences, Shanghai University, Shanghai 200444, China; \\ chenjiabo@shu.edu.cn \\ 3 School of Materials Science and Engineering, Shanghai University, Shanghai 200444, China; \\ 20820257@shu.edu.cn \\ 4 Department of Physics, College of Sciences, Shanghai University, Shanghai 200444, China; \\ SHUXieyao@shu.edu.cn \\ * Correspondence: lnsun@shu.edu.cn
}

Citation: Wang, Z.; Sun, G.; Chen, J.; Xie, Y.; Jiang, H.; Sun, L. Upconversion Luminescent Humidity Sensors Based on Lanthanide-Doped MOFs. Chemosensors 2022, 10, 66 . https://doi.org/10.3390/ chemosensors10020066

Academic Editor: Ambra Giannetti

Received: 30 December 2021

Accepted: 31 January 2022

Published: 7 February 2022

Publisher's Note: MDPI stays neutral with regard to jurisdictional claims in published maps and institutional affiliations.

Copyright: (C) 2022 by the authors. Licensee MDPI, Basel, Switzerland. This article is an open access article distributed under the terms and conditions of the Creative Commons Attribution (CC BY) license (https:// creativecommons.org/licenses/by/ $4.0 /)$.

\begin{abstract}
Lanthanide-doped metal-organic frameworks ( $\mathrm{Y} / \mathrm{Yb} / \mathrm{Er}-\mathrm{MOF})$ were synthesized by a low-cost solvothermal method. The obtained $\mathrm{Y} / \mathrm{Yb} / \mathrm{Er}-\mathrm{MOF}$ shows the cooperative upconversion luminescence of $\mathrm{Yb}^{3+}$ and upconversion luminescence of $\mathrm{Er}^{3+}\left(\mathrm{Yb}^{3+}\right.$-sensitized) irradiated by a continuous wave $980 \mathrm{~nm}$ laser. In order to explore the potential application of $\mathrm{Y} / \mathrm{Yb} / \mathrm{Er}-\mathrm{MOF}$ in relative humidity $(\mathrm{RH})$ sensors, the $\mathrm{RH}$ responsiveness of $\mathrm{Y} / \mathrm{Yb} /$ Er-MOF was investigated by measuring the intensity changes of upconversion luminescence. The $\mathrm{Y} / \mathrm{Yb} /$ Er-MOF possesses two luminescence centers, in which $\mathrm{Yb}^{3+}$ forms emission at $500 \mathrm{~nm}$ through the cooperative luminescence effect, and $\mathrm{Er}^{3+}$ achieves $660 \mathrm{~nm}$ emission through excited state absorption and successive energy transfer from $\mathrm{Yb}^{3+}$. Hence, the ratio meter luminescence sensor for $\mathrm{RH}$ is constructed based on $\mathrm{Y} / \mathrm{Yb} / \mathrm{Er}-\mathrm{MOF}$. The results show that the response of $\mathrm{Y} / \mathrm{Yb} / \mathrm{Er}-\mathrm{MOF}$ to $\mathrm{RH}$ presents a linear relationship in the range of $11-95 \%$. The cycle stability of $\mathrm{Y} / \mathrm{Yb} / \mathrm{Er}-\mathrm{MOF}$ responses to $\mathrm{RH}$ was investigated with the intensity changes of upconversion luminescence, and the recovery ratio was more than $93 \%$ each time. Therefore, the $\mathrm{Y} / \mathrm{Yb} / \mathrm{Er}-\mathrm{MOF}$ is a humidity-sensitive material with great potential for applications such as humidity sensors.
\end{abstract}

Keywords: upconversion luminescence; lanthanide luminescence; lanthanide-doped metal-organic frameworks; humidity sensor

\section{Introduction}

Humidity is a physical quantity that indicates the degree of air dryness. The less water vapor in a certain air volume at a certain temperature, the drier the air; the more water vapor, the more humid. Humidity is often expressed by relative humidity (RH), comparative humidity, mixing ratio, saturation difference, and dew point. Especially, RH is the ratio percentage of the actual water vapor pressure in the air to the saturated water vapor pressure at the current temperature, which is also the most common form of humidity. The $\mathrm{RH}$ of $50 \%$ air contains half as much water vapor as the saturation point at the same temperature. Air with an $\mathrm{RH}$ of $100 \%$ is saturated with water vapor. Water vapor in the air generally condenses out when the relative humidity exceeds $100 \%$.

Humidity sensors are widely used in industry, agriculture, food and pharmaceutical storage, meteorology, medical health, aviation, etc. [1-4]. Due to the difference in the application environment, various types of humidity sensors have been developed to satisfy the requirements of different applications. Common humidity sensors can be divided into two main categories according to the signal used to transmit information: electronic 
and optical [5]. Materials used to construct humidity sensors typically include ceramics, semiconductors, and polymers, each with different advantages and limitations [6-8]. Opticsbased humidity sensors are generally more sensitive than electronic-based ones and can be tailored to different application environments with the well-known advantages of electromagnetic interference resistance and electrical inertia [5]. However, at present, the development of humidity sensing materials with high sensitivity to a wide range of humidities remains a major challenge.

Metal-organic framework materials (MOFs) are a type of coordination polymer that developed rapidly in the past two decades. MOFs usually possess a three-dimensional pore structure, with metal ions as the connection point and organic ligands to support to form three-dimensional spatial extension. MOFs are a type of important new porous material widely used in catalysis, energy storage, and separation. Lanthanide-doped MOFs are one of the most promising luminescence materials for humidity sensors, which possess the properties of large specific surface area and structural stability of MOFs and retain the unique luminescent properties of lanthanides $[9,10]$. The large specific surface area benefits from interacting more effectively with analytes (e.g., water molecules) for MOFs, thus improving the sensitivity and response speed of the sensor [11-13]. Lanthanide ions exhibit visible luminescence with narrow emission bands and high color purity due to their unique electronic structure, abundant electron energy levels, and long-life excited states $[14,15]$. Therefore, lanthanide-doped MOFs have attracted much attention as an attractive candidate material that can be used to develop humidity sensors.

Photoluminescence is a luminescence phenomenon produced by the excitation of a luminescent material with ultraviolet, visible, or near-infrared light. The lanthanide luminescence phenomenon can be divided into upconversion luminescence and downshifting luminescence depending on the difference between the excitation wavelength and the corresponding emitted light [16-18]. Upconversion luminescence, an anti-Stokes luminescence phenomenon, refers to the material being irradiated by low-energy light and emitting with high-energy light. Conversely, downshifting luminescence occurs $[19,20]$. In addition, the lanthanide luminescence is closely related to the chemical environment in which the luminescent center is located, as such the surrounding high-energy $\mathrm{O}-\mathrm{H}$, $\mathrm{N}-\mathrm{H}$, and $\mathrm{C}-\mathrm{H}$ vibrations will affect the luminescence intensity [21-23]. Based on this phenomenon, it is possible to design and synthesize optical sensors for small molecule species (e.g., water). Currently, those reported on lanthanide-doped MOFs as humidity sensing materials are usually a downshifting luminescence process using high-energy light excitation to emit low-energy light [24,25]. In contrast, the upconversion luminescence of lanthanide-doped MOFs is rarely reported, especially for humidity sensor application.

Herein, we develop an upconversion luminescence humidity sensor based on the designed and synthesized $\mathrm{Y} / \mathrm{Yb} / \mathrm{Er}-\mathrm{MOF}$. Luminescence sensing over a wide $\mathrm{RH}$ range $(11-95 \%)$ is achieved using the variation of upconversion luminescence intensity of $\mathrm{Y} / \mathrm{Yb} / \mathrm{Er}-$ MOF. The cycle stability is good based on the intensity changes of upconversion luminescence, and the recovery ratio is more than $93 \%$ each time.

\section{Materials and Methods}

All chemical materials and characterizations used in this work are listed in the Supporting Information.

\subsection{Synthesis of Lanthanide-Doped MOFs (Denoted as Y/Yb/Er-MOF)}

$\mathrm{Y} / \mathrm{Yb} /$ Er-MOF was synthesized by the hydrothermal method. A mixture of $2 \mathrm{mmol}$ $\mathrm{LnCl}_{3}\left(\mathrm{Y}^{3+}: \mathrm{Yb}^{3+}: \mathrm{Er}^{3+}=78: 20: 2\right), 1 \mathrm{mmol}$ 1,3,5-benzenetricarboxylate (BTC), $16 \mathrm{~mL}$ dimethylformamide (DMF), and $8 \mathrm{~mL}$ deionized water were added to a $50 \mathrm{~mL}$ Teflon-lined autoclave, stirring for $2 \mathrm{~h}$ at room temperature. Afterward, the Teflon-lined autoclave was sealed and heated at $150{ }^{\circ} \mathrm{C}$ for $12 \mathrm{~h}$ and then naturally cooled down to room temperature. The resulting mixture was filtered via suction filtration and washed with DMF and ethanol, 
respectively, until all remaining precursors and by-products were removed. The final product was dried in a vacuum oven at $80^{\circ} \mathrm{C}$ for $12 \mathrm{~h}$.

\section{2. $Y / Y b / E r-M O F$ Responses to Different RH Environments}

The obtained $\mathrm{Y} / \mathrm{Yb} / \mathrm{Er}-\mathrm{MOF}$ was fully ground and placed in a sample tank of solid powder, and then the $\mathrm{Y} / \mathrm{Yb} / \mathrm{Er}-\mathrm{MOF}$ was dried under the oven at $110^{\circ} \mathrm{C}$ for $1 \mathrm{~h}$. Different supersaturated aqueous solutions controlled the different $\mathrm{RH}$ environments at room temperature. The supersaturated aqueous solutions of $\mathrm{LiCl}, \mathrm{MgCl}_{2}, \mathrm{Mg}\left(\mathrm{NO}_{3}\right)_{2}, \mathrm{NaCl}$, $\mathrm{KCl}$, and $\mathrm{KNO}_{3}$ at room temperature were obtained and separately kept in six closed conical flasks $(250 \mathrm{~mL})$. The corresponding RH was determined with a humidity meter as $11 \%, 33 \%, 54 \%, 75 \%, 85 \%$, and 95\%, respectively [26-28]. In order to obtain reliable RH sensing performance, $\mathrm{Y} / \mathrm{Yb} / \mathrm{Er}-\mathrm{MOF}$ was placed directly in a flask with different $\mathrm{RH}$ after vacuum drying. After being kept for $30 \mathrm{~min}$, it was quickly removed and placed into the spectrometer to obtain the corresponding upconversion luminescence spectrum.

\section{Results and Discussion}

\subsection{Characterization of Structural Properties}

The morphology of $\mathrm{Y} / \mathrm{Yb} / \mathrm{Er}-\mathrm{MOF}$ was characterized by scanning electron microscopy (SEM) and transmission electron microscopy (TEM), as shown in Figure 1a and Figure S1, respectively. It shows that $\mathrm{Y} / \mathrm{Yb} / \mathrm{Er}-\mathrm{MOF}$ present a rectangular prismatic morphology with an average particle size of around $20 \mu \mathrm{m}$. X-ray diffraction (XRD) spectra were used to analyze the crystal structure of the synthesized $\mathrm{Y} / \mathrm{Yb} / \mathrm{Er}-\mathrm{MOF}$. As shown in Figure 1b, the diffraction pattern of $\mathrm{Y} / \mathrm{Yb} / \mathrm{Er}-\mathrm{MOF}$ is consistent with the previous results of $\mathrm{Y}-\mathrm{BTC}$ MOF [29], indicating that the crystal structure of BTC-MOFs matrix material is unchanged after being doped with $\mathrm{Yb}^{3+}$ and $\mathrm{Er}^{3+}$. The crystal structures of $\mathrm{Y} / \mathrm{Yb} / \mathrm{Er}-\mathrm{MOF}$, in this case, and Y-BTC-MOF, are isomorphic and can be attributed to the tetragonal crystal system. The lanthanide ions are coordinated with $\mathrm{O}$ atoms from BTC. In this way, the MOFs structure is constructed [29]. In addition, energy dispersive spectroscopy (EDS) point scanning (inset of Figure 1a), as well as elemental mapping images of $\mathrm{Y} / \mathrm{Yb} / \mathrm{Er}-\mathrm{MOF}$ (Figure 1c), were used to investigate the chemical composition and elemental distribution of $\mathrm{Y} / \mathrm{Yb} / \mathrm{Er}-\mathrm{MOF}$. The results provided further evidence that the elements of $\mathrm{C}, \mathrm{O}, \mathrm{Y}, \mathrm{Yb}$, and Er exist in $\mathrm{Y} / \mathrm{Yb} / \mathrm{Er}-\mathrm{MOF}$. Furthermore, the EDS (inset of Figure 1a) results showed that the elements of $\mathrm{C}, \mathrm{O}, \mathrm{Y}, \mathrm{Yb}, \mathrm{Er}$, and Pt exist in the $\mathrm{Y} / \mathrm{Yb} / \mathrm{Er}-\mathrm{MOF}$, of which the Pt element is caused by spraying platinum during the SEM measurement process.
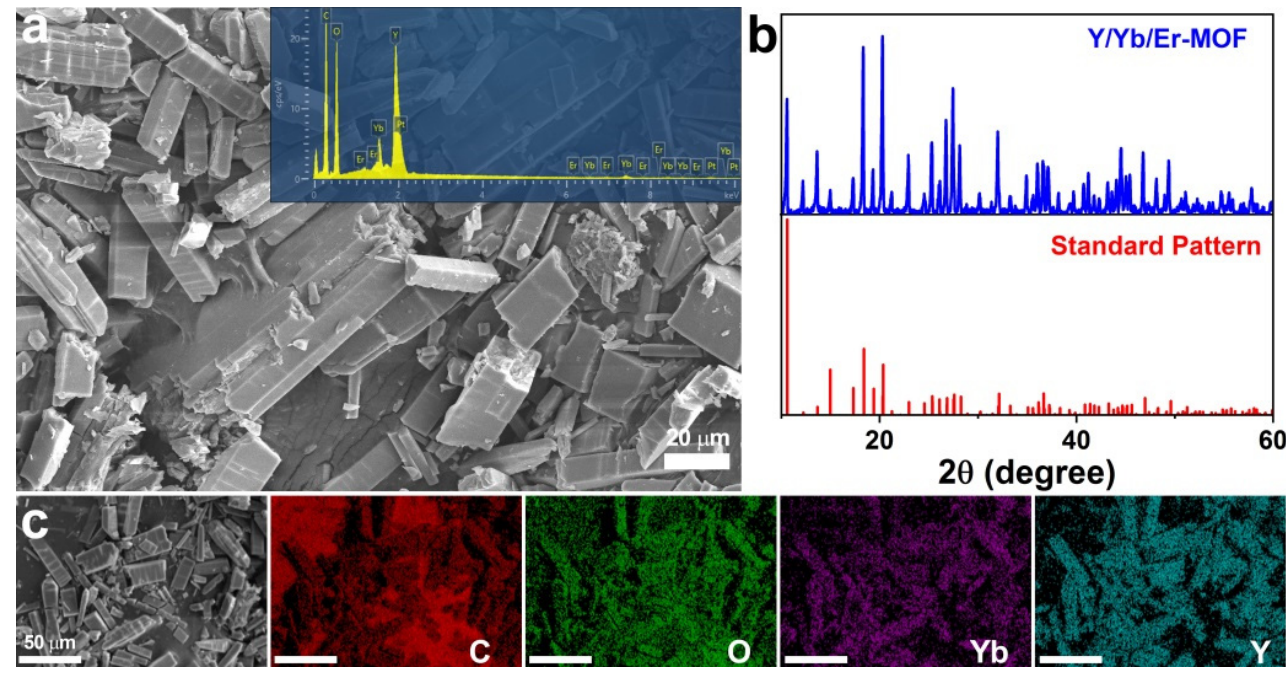

Figure 1. The morphology and the crystal structure of $\mathrm{Y} / \mathrm{Yb} / \mathrm{Er}-\mathrm{MOF}$. (a) Scanning electron microscopy (SEM) image of $\mathrm{Y} / \mathrm{Yb} / \mathrm{Er}-\mathrm{MOF}$, the inset is energy dispersive spectroscopy (EDS) point scanning of $\mathrm{Y} / \mathrm{Yb} / \mathrm{Er}-\mathrm{MOF}$. (b) X-ray diffraction $(\mathrm{XRD})$ pattern of $\mathrm{Y} / \mathrm{Yb} / \mathrm{Er}-\mathrm{MOF}$, and the standard 
pattern of Y-BTC-MOF (Reprinted with permission from "Luo, J.; Xu, H.; Liu, Y.; Zhao, Y.; Daemen, L.L.; Brown, C.; Timofeeva, T.V.; Ma, S.; Zhou, H.-C. Hydrogen Adsorption in a Highly Stable Porous Rare-Earth Metal-Organic Framework: Sorption Properties and Neutron Diffraction Studies. J. Am. Chem. Soc. 2008, 130, 9626-9627, doi:10.1021/ja801411f". Copyright 2008, American Chemical Society.) [29]. (c) The corresponding elemental mapping images of $\mathrm{Y} / \mathrm{Yb} / \mathrm{Er}-\mathrm{MOF}$.

Figure S2 display the Fourier transform infrared spectra (FTIR) of Y/Yb/Er-MOF and BTC. The spectrum of $\mathrm{Y} / \mathrm{Yb} /$ Er-MOF shows the characteristic peaks of dimethylformamide (DMF). The peaks observed at 2960 and $2880 \mathrm{~cm}^{-1}$ can be attributed to the asymmetric stretching vibration and symmetric stretching vibration of the methyl group, respectively. Furthermore, the peak at $1640 \mathrm{~cm}^{-1}$ corresponds to the carbonyl group of DMF and BTC. The wide peak at $3450 \mathrm{~cm}^{-1}$ is attributed to the $-\mathrm{OH}$ vibration of $\mathrm{H}_{2} \mathrm{O}$, indicating that $\mathrm{Y} / \mathrm{Yb} /$ Er-MOF contains $\mathrm{H}_{2} \mathrm{O}$ molecules. The peak at $1100 \mathrm{~cm}^{-1}$ can be attributed to the $\mathrm{C}-\mathrm{C}$ planar skeleton vibration of the aromatic ring, suggesting the presence of the BTC linker [29].

\subsection{Upconversion Luminescence of $Y / Y b / E r-M O F$}

The UV-vis absorption spectra of $\mathrm{Y} / \mathrm{Yb} / \mathrm{Er}-\mathrm{MOF}$ and BTC are shown in Figure S3. The spectrum of $\mathrm{Y} / \mathrm{Yb} / \mathrm{Er}-\mathrm{MOF}$ retains the same absorption peak with BTC, yet a new peak appears around $980 \mathrm{~nm}$, caused by the participation of $\mathrm{Yb}^{3+}$ and $\mathrm{Er}^{3+}$ in forming the MOFs structure. Considering the absorption of $\mathrm{Y} / \mathrm{Yb} /$ Er-MOF in the near-infrared (NIR) band, we deduce that the $\mathrm{Y} / \mathrm{Yb} / \mathrm{Er}-\mathrm{MOF}$ can be excited by the NIR laser to obtain the corresponding upconversion luminescence spectrum. As expected, Figure 2a show the upconversion luminescence spectrum of $\mathrm{Y} / \mathrm{Yb} / \mathrm{Er}-\mathrm{MOF}$ irradiated by a continuous wave $980 \mathrm{~nm}$ laser, which shows three characteristic peaks at $500 \mathrm{~nm}, 520 \mathrm{~nm}$, and $660 \mathrm{~nm}$ of lanthanide ions, respectively.

a

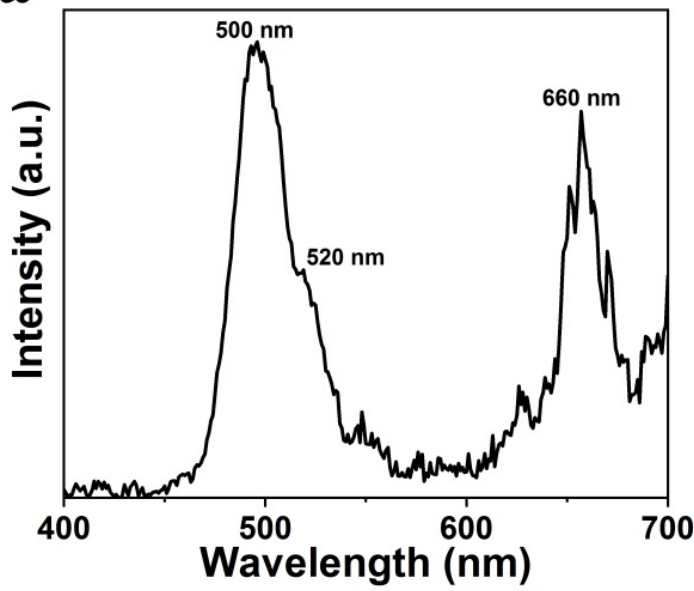

b

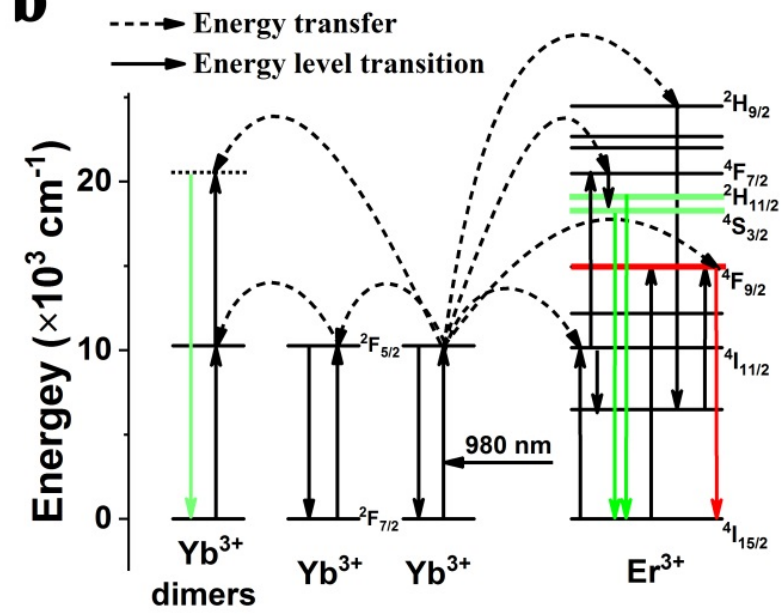

Figure 2. (a) The upconversion luminescence spectrum of $\mathrm{Y} / \mathrm{Yb} /$ Er-MOF irradiated by a continuous wave $980 \mathrm{~nm}$ laser $\left(\lambda_{\mathrm{ex}}=980 \mathrm{~nm}, 2.0 \mathrm{~W}\right)$. (b) Schematic energy level diagram of $\mathrm{Y} / \mathrm{Yb} / \mathrm{Er}-\mathrm{MOF}$ with the possible energy transfer paths.

The emission peak is observed in the visible region with the maximum emission peak at around $500 \mathrm{~nm}$, caused by the cooperative luminescence of $\mathrm{Yb}^{3+}$ clusters. Cooperative luminescence usually describes the process by which a pair of ions emit a single photon by simultaneous reduction from its excited state. Cooperative luminescence represents a special type of electron transition that occurs in a spectral region where a single ion has no absorption or emission. Cooperative luminescence was first demonstrated in 1970 with a pair of excited $\mathrm{Yb}^{3+}$ ions [30]. Since then, the $\mathrm{Yb}^{3+}$-dimers have been widely explored for applications due to their unique electron configuration, such as scintillators, solid structure 
probes, and optical bistability [31-36]. In order to determine the origin of the upconversion luminescence signal, in this case, the upconversion luminescence intensity was recorded as a function of excitation power density (Figure 3a) by a conventional Log/Log curve with a linear fit slope of 2.2 (Figure $3 b$ ), indicating a two-photon process that is expected for $\mathrm{Yb}^{3+}$-dimers.

a

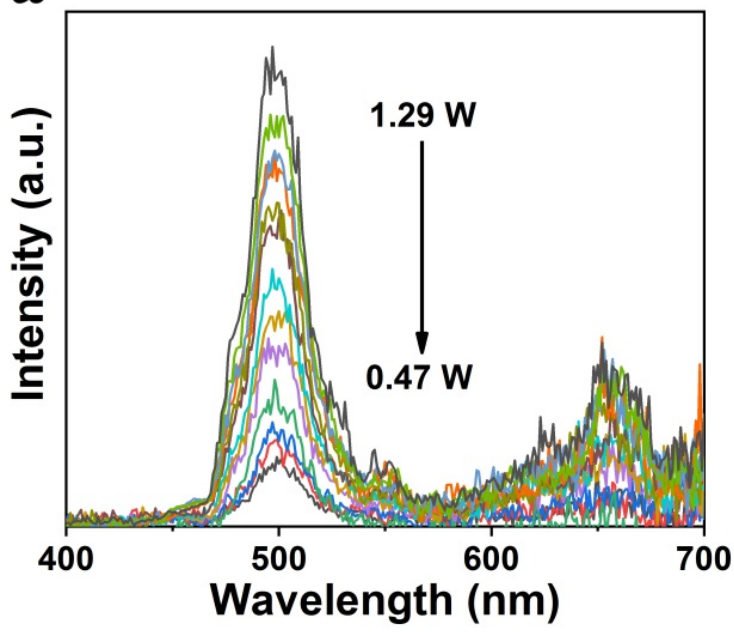

b

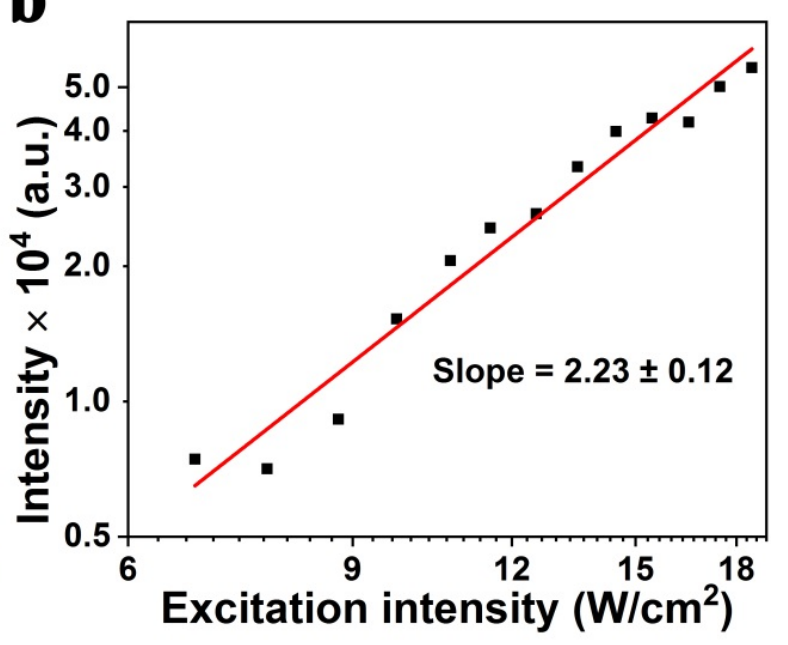

Figure 3. (a) The upconversion luminescence spectra of $\mathrm{Y} / \mathrm{Yb} / \mathrm{Er}-\mathrm{MOF}$ irradiated with different laser power $\left(0.47-1.29 \mathrm{~W}, \lambda_{\mathrm{ex}}=980 \mathrm{~nm}\right)$. (b) Log/Log plot of upconversion luminescence intensity at $500 \mathrm{~nm}$ as a function of different power densities of the laser $\left(\lambda_{\mathrm{ex}}=980 \mathrm{~nm}\right)$.

In addition, the upconversion luminescence spectrum of $\mathrm{Y} / \mathrm{Yb} /$ Er-MOF (Figure 2a) shows characteristic emission peaks $\left(520 \mathrm{~nm}\right.$ and $660 \mathrm{~nm}$ ) of $\mathrm{Er}^{3+}$ ions. As shown in Figure $2 \mathrm{~b}$, after being irradiated by a continuous wave $980 \mathrm{~nm}$ laser, $\mathrm{Yb}^{3+}$ in $\mathrm{Y} / \mathrm{Yb} / \mathrm{Er}-\mathrm{MOF}$ absorbs energy and occupies the excited state ${ }^{2} \mathrm{~F}_{5 / 2}$. Subsequently, the non-radiant energy transfer occurs between the excited state of $\mathrm{Yb}^{3+}$ and the ground state of $\mathrm{Er}^{3+}\left({ }^{4} \mathrm{I}_{15 / 2}\right)$. After that, $\mathrm{Er}^{3+}$ achieves the excited state $\left({ }^{4} \mathrm{I}_{15 / 2} \rightarrow{ }^{4} \mathrm{I}_{11 / 2}\right)$, and $\mathrm{Yb}^{3+}$ returns to the ground state $\left({ }^{2} \mathrm{~F}_{7 / 2}\right)$. Due to its unique outermost electron configuration, the $\mathrm{Er}^{3+}$ ion possesses abundant energy levels corresponding to the different excited states. The excited $\mathrm{Er}^{3+} \mathrm{can}$ be further pumped to a higher energy level excited state through excited state absorption and successive energy transfer from $\mathrm{Yb}^{3+}$, thus forming emissions at $520 \mathrm{~nm}\left({ }^{2} \mathrm{H}_{11 / 2} \rightarrow\right.$ $\left.{ }^{4} \mathrm{I}_{15 / 2}\right)$ and $660 \mathrm{~nm}\left({ }^{4} \mathrm{~F}_{9 / 2} \rightarrow{ }^{4} \mathrm{I}_{15 / 2}\right)$.

Therefore, as presented in Figure $2 \mathrm{a}$, there are two luminescence centers during the upconversion luminescence process of $\mathrm{Y} / \mathrm{Yb} / \mathrm{Er}-\mathrm{MOF}$. One luminescence center is $\mathrm{Yb}^{3+}$, which forms emission at $500 \mathrm{~nm}$ through the cooperative luminescence effect. The other luminescence center is $\mathrm{Er}^{3+}$, which results in emissions at 520 and $660 \mathrm{~nm}$ that are sensitized by the $\mathrm{Yb}^{3+}$ ion.

\subsection{Response of $\mathrm{Y} / \mathrm{Yb} / \mathrm{Er}-\mathrm{MOF}$ to Relative Humidity (RH)}

As mentioned above, the three emission peaks of the upconversion luminescence of $\mathrm{Y} / \mathrm{Yb} / \mathrm{Er}-\mathrm{MOF}$ are composed by the cooperative luminescence effect of $\mathrm{Yb}^{3+}(500 \mathrm{~nm})$ and the upconversion luminescence of $\mathrm{Er}^{3+}$ center (520 and $620 \mathrm{~nm}$ ), respectively. Therefore, it can be deduced that the luminescence process can be divided into two stages. The first stage is from the ground state $\left({ }^{2} \mathrm{~F}_{7 / 2}\right)$ to the excited state $\left({ }^{2} \mathrm{~F}_{5 / 2}\right)$ of $\mathrm{Yb}^{3+}$ after irradiation by a $980 \mathrm{~nm}$ laser. The second stage is that the excited state $\left({ }^{2} \mathrm{~F}_{5 / 2}\right)$ of $\mathrm{Yb}^{3+}$ transmits the energy to realize its own cooperative luminescence and sensitizes the upconversion luminescence of $\mathrm{Er}^{3+}$. The surrounding chemical environment of the luminescence centers will affect the energy transfer process during the second stage. If there are water molecules around $\mathrm{Yb}^{3+}$, the vibration of $-\mathrm{OH}$ with high energy will absorb part of the energy transferred from the excited state of $\mathrm{Yb}^{3+}$, which will quench the upconversion luminescence of $\mathrm{Y} / \mathrm{Yb} / \mathrm{Er}-\mathrm{MOF}$. 
Moreover, the three-dimensional pore structure of the MOFs can allow the water molecules to enter the pore and uniform the distribution of water molecules around the lanthanide ions. Thus, based on the above analysis, an optical humidity sensor can be constructed using the $\mathrm{Y} / \mathrm{Yb} / \mathrm{Er}-\mathrm{MOF}$.

Then, the response of $\mathrm{Y} / \mathrm{Yb}$ /Er-MOF to $\mathrm{RH}$ was investigated by measuring the upconversion luminescence spectra of $\mathrm{Y} / \mathrm{Yb} / \mathrm{Er}-\mathrm{MOF}$ in different $\mathrm{RH}$ environments. Figure $4 \mathrm{a}$ show the real-time response of the spectra of $\mathrm{Y} / \mathrm{Yb} / \mathrm{Er}-\mathrm{MOF}$ with different $\mathrm{RH}$ environments. The emission intensity at 500 and $660 \mathrm{~nm}$ gradually decreases with the rise of $\mathrm{RH}$, which is displayed in a linear dose-dependent manner (Figure $4 \mathrm{~b}, \mathrm{c}$ ). It can be deduced that the $\mathrm{Y} / \mathrm{Yb} / \mathrm{Er}-\mathrm{MOF}$ can respond to different RH environments in the RH range of $11-95 \%$.
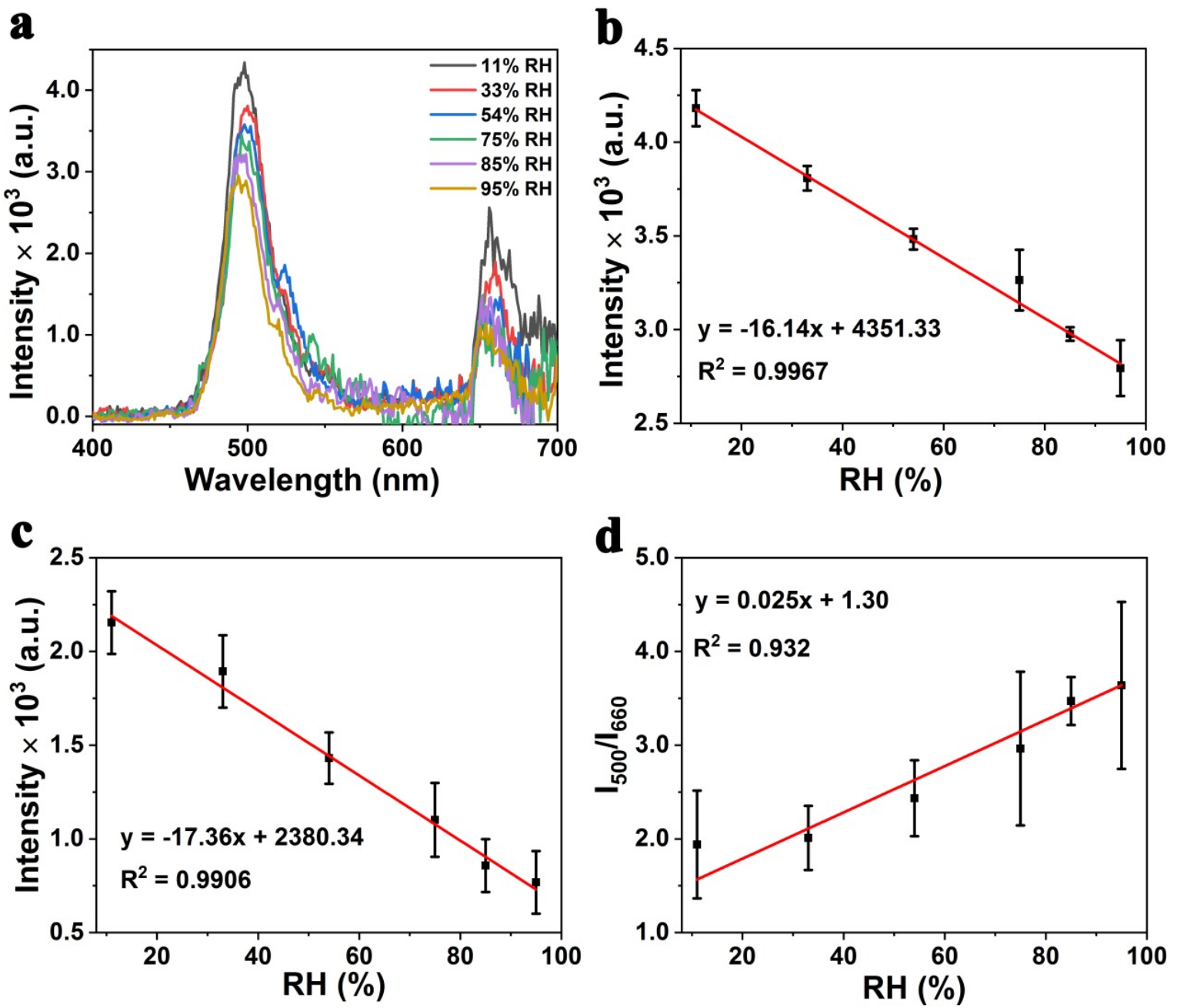

Figure 4. (a) The real-time response of the upconversion luminescence spectra $\left(\lambda_{\mathrm{ex}}=980 \mathrm{~nm}, 1.5 \mathrm{~W}\right)$ of $\mathrm{Y} / \mathrm{Yb} / \mathrm{Er}-\mathrm{MOF}$ with different relative humidity $(\mathrm{RH})$ environments (11-95\% RH). (b) The change of upconversion luminescence intensity at $500 \mathrm{~nm}$ versus various $\mathrm{RH}$ is shown in (a). (c) The change of upconversion luminescence intensity at $660 \mathrm{~nm}$ versus various $\mathrm{RH}$ is shown in (a). (d) The upconversion luminescence intensity ratio $\left(I_{500} / I_{660}\right)$ versus various $R H$.

The slopes of the linear relationship are different with the recorded upconversion luminescence intensity at 500 and $660 \mathrm{~nm}$, respectively, indicating that the intensity at $660 \mathrm{~nm}$ is more sensitive to RH than that at $500 \mathrm{~nm}$, which is consistent with the discussion of the $\mathrm{Er}^{3+}$ luminescence mechanism. As mentioned above, the upconversion luminescence at $660 \mathrm{~nm}$ is the characteristic emission of $\mathrm{Er}^{3+}$ ions, and the upconversion process is sensitized by $\mathrm{Yb}^{3+}$. Thus, based on the different slopes, the linear relationship between different $\mathrm{RH}$ and corresponding luminescence intensity ratios of $\mathrm{I}_{500} / \mathrm{I}_{660}$ is plotted (Figure $4 \mathrm{~d}$ ). 
The result shows that the $\mathrm{Y} / \mathrm{Yb} / \mathrm{Er}-\mathrm{MOF}$ constructs a ratio meter sensor for $\mathrm{RH}$ based on upconversion luminescence.

Furthermore, the cycle stability of $\mathrm{Y} / \mathrm{Yb} / \mathrm{Er}-\mathrm{MOF}$ was investigated by measuring the upconversion luminescence spectra of $\mathrm{Y} / \mathrm{Yb} / \mathrm{Er}-\mathrm{MOF}$ with and without the $95 \% \mathrm{RH}$ environment, respectively. With $95 \% \mathrm{RH}$, the upconversion luminescence intensity was recorded after the $\mathrm{Y} / \mathrm{Yb} / \mathrm{Er}-\mathrm{MOF}$ was kept in a 95\% RH environment for $30 \mathrm{~min}$. Without $95 \% \mathrm{RH}$ denotes that the upconversion luminescence intensity was recorded after the $\mathrm{Y} / \mathrm{Yb} / \mathrm{Er}-\mathrm{MOF}$ was dried under the oven at $110{ }^{\circ} \mathrm{C}$ for $1 \mathrm{~h}$. This kind of cycle was repeated 10 times, as shown in Figure 5, and recorded for the luminescence intensity at both $500 \mathrm{~nm}$ and $660 \mathrm{~nm}$. The recovery ratio of each cycle is more than $93 \%$ each time. The results indicate that the cycle stability of the $\mathrm{Y} / \mathrm{Yb} / \mathrm{Er}-\mathrm{MOF}$ response to $\mathrm{RH}$ is excellent. Thus, $\mathrm{Y} / \mathrm{Yb} / \mathrm{Er}-\mathrm{MOF}$ can be a desirable candidate for luminescence materials for humidity sensors.

a

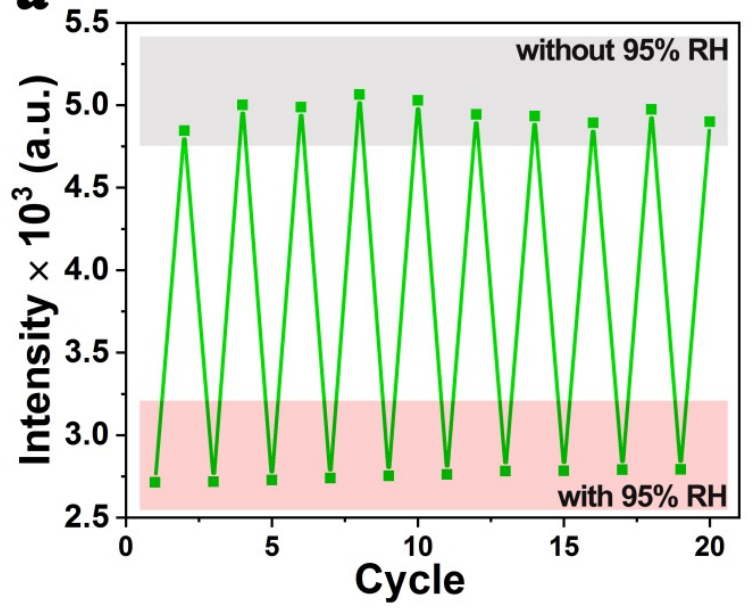

b

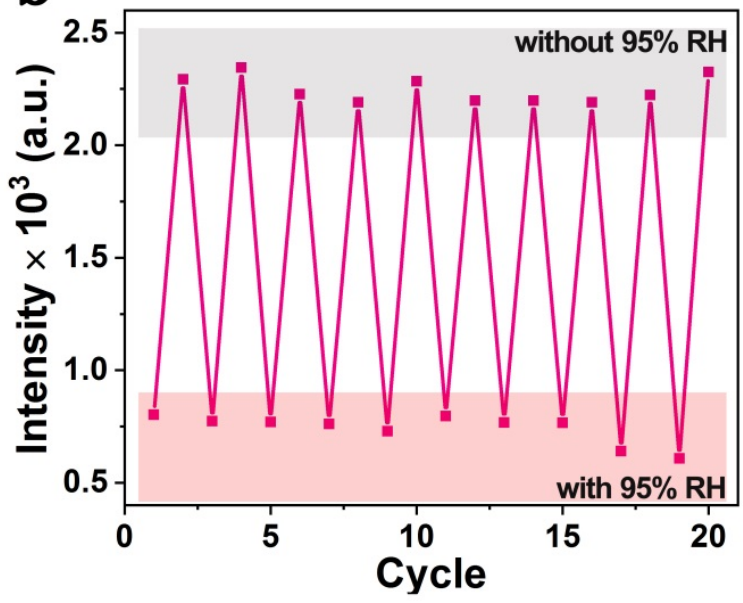

Figure 5. The cycle stability of $\mathrm{Y} / \mathrm{Yb}$ /Er-MOF responds to relative humidity (RH). With $95 \% \mathrm{RH}$, the upconversion luminescence intensity was recorded after the $\mathrm{Y} / \mathrm{Yb} / \mathrm{Er}-\mathrm{MOF}$ was kept in a $95 \%$ RH environment for $30 \mathrm{~min}$. Without $95 \%$ RH means the upconversion luminescence intensity was recorded after the $\mathrm{Y} / \mathrm{Yb} / \mathrm{Er}-\mathrm{MOF}$ was dried under the oven at $110^{\circ} \mathrm{C}$ for $1 \mathrm{~h}$. The upconversion luminescence intensities were recorded at $500 \mathrm{~nm}(\mathbf{a})$ and $660 \mathrm{~nm}$ (b) for ten cycles, respectively.

\section{Conclusions}

In summary, we have demonstrated a luminescence humidity sensor based on lanthanidedoped MOFs using upconversion luminescence signals in response to relative humidity changes. The $\mathrm{Y} / \mathrm{Yb} / \mathrm{Er}-\mathrm{MOF}$ was synthesized by the solvothermal method. With the two luminescence centers $\left(\mathrm{Yb}^{3+}\right.$ and $\left.\mathrm{Er}^{3+}\right)$ during the upconversion process, a ratio meter luminescence sensor for $\mathrm{RH}$ is constructed based on $\mathrm{Y} / \mathrm{Yb} / \mathrm{Er}-\mathrm{MOF}$. An analysis of the upconversion luminescence spectra shows that $\mathrm{Y} / \mathrm{Yb} / \mathrm{Er}-\mathrm{MOF}$ is able to respond linearly to $\mathrm{RH}$ in the range of $11-95 \%$ with wonderful cycle stability. The recovery ratio of each cycle is more than $93 \%$ each time. The excellent humidity sensing performance of $\mathrm{Y} / \mathrm{Yb} / \mathrm{Er}-\mathrm{MOF}$ is caused by the framework structure of MOFs and the sensitivity of lanthanide luminescence to the environment. Therefore, this work makes lanthanide-doped $\mathrm{Y} / \mathrm{Yb} / \mathrm{Er}-\mathrm{MOF}$ attractive as an effective optical humidity sensor for humidity detection, which will broaden the applications of lanthanide-doped MOFs materials.

Supplementary Materials: The followings are available online at https:/ / www.mdpi.com/article/ 10.3390/chemosensors10020066/s1, Figure S1: Transmission electron microscopy images of Y/Yb/ErMOF with different magnifications; Figure S2: Fourier transform infrared spectroscopy spectra of $\mathrm{Y} / \mathrm{Yb}$ /Er-MOF and BTC; Figure S3: The UV-visible absorption spectra of Y/Yb/Er-MOF and BTC. 


\begin{abstract}
Author Contributions: Conceptualization, Z.W., H.J. and L.S.; methodology, Z.W. and G.S.; validation, Z.W., H.J. and L.S.; formal analysis, Z.W., J.C. and Y.X.; investigation, Z.W. and J.C.; data curation, Z.W. and Y.X.; writing—original draft preparation, Z.W.; writing—review and editing, G.S., H.J. and L.S.; supervision, H.J. and L.S.; funding acquisition, L.S. All authors have read and agreed to the published version of the manuscript.
\end{abstract}

Funding: This research was funded by the National Natural Science Foundation of China (Grant No. 51872183) and "Shuguang Program" supported by the Shanghai Education Development Foundation and Shanghai Municipal Education Commission (19SG38).

Institutional Review Board Statement: Not applicable.

Informed Consent Statement: Not applicable.

Acknowledgments: Many thanks to Pengfei Hu (Shanghai University) for his useful measurements and discussion. We are also grateful to the Instrumental Analysis and Research Center of Shanghai University.

Conflicts of Interest: The authors declare no conflict of interest.

\title{
References
}

1. Cho, M.Y.; Kim, S.; Kim, I.S.; Kim, E.S.; Wang, Z.J.; Kim, N.Y.; Kim, S.W.; Oh, J.M. Perovskite-Induced Ultrasensitive and Highly Stable Humid-ity Sensor Systems Prepared by Aerosol Deposition at Room Temperature. Adv. Funct. Mater. 2019, 30, 1907449. [CrossRef]

2. Lan, L.; Le, X.; Dong, H.; Xie, J.; Ying, Y.; Ping, J. One-step and large-scale fabrication of flexible and wearable humidity sensor based on laser-induced graphene for real-time tracking of plant transpiration at bio-interface. Biosens. Bioelectron. 2020, 165, 112360. [CrossRef]

3. Peng, Y.; Zhao, Y.; Chen, M.-Q.; Xia, F. Research Advances in Microfiber Humidity Sensors. Small 2018, 14, e1800524. [CrossRef] [PubMed]

4. Torres Alonso, E.; Shin, D.W.; Rajan, G.; Neves, A.I.S.; Russo, S.; Craciun, M.F. Water-Based Solution Processing and Wafer-Scale Integration of All-Graphene Humidity Sensors. Adv. Sci. 2019, 6, 1802318. [CrossRef] [PubMed]

5. Rao, X.; Zhao, L.; Xu, L.; Wang, Y.; Liu, K.; Wang, Y.; Chen, G.Y.; Liu, T.; Wang, Y. Review of Optical Humidity Sensors. Sensors 2021, 21, 8049. [CrossRef] [PubMed]

6. $\quad$ Boudaden, J.; Steinmaßl, M.; Endres, H.-E.; Drost, A.; Eisele, I.; Kutter, C.; Müller-Buschbaum, P. Polyimide-Based Capacitive Humidity Sensor. Sensors 2018, 18, 1516. [CrossRef] [PubMed]

7. Ionete, E.I.; Spiridon, S.-I.; Monea, B.-F.; Ebrasu-Ion, D.; Vaseashta, A. SWCNT-Pt-P $\mathrm{O}_{5}$-Based Sensor for Humidity Measurements. IEEE Sens. J. 2016, 16, 7593-7599. [CrossRef]

8. Liu, Z.; Zhang, M.; Zhang, Y.; Zhang, Y.; Liu, K.; Zhang, J.; Yang, J.; Yuan, L. Spider silk-based humidity sensor. Opt. Lett. 2019, 44, 2907-2910. [CrossRef]

9. Yue, D.; Zhang, J.; Zhao, D.; Lian, X.; Cui, Y.; Yang, Y.; Qian, G. Ratiometric near infrared luminescent thermometer based on lan-thanide metal-organic frameworks. J. Solid State Chem. 2016, 241, 99-104. [CrossRef]

10. Zhang, P.; Song, N.; Liu, S.; Li, Q.; Wang, Y.; Zhou, B. Tuning the photoluminescence of lanthanide metal-organic framework nanospheres through ligand-induced phase transition towards sensing. J. Mater. Chem. C 2021, 9, 6208-6216. [CrossRef]

11. Fang, Z.; Chen, D.; Li, Z.; Ma, X.; Wan, X.; Deng, Z.; Peng, X. A self-confinement synthesis of a POM-decorated MOF thin film for actively hydrolyzing ethyl acetate. Chem. Commun. 2020, 56, 13840-13843. [CrossRef] [PubMed]

12. Liu, H.; Peng, H.; Xin, Y.; Zhang, J. Metal-organic frameworks: A universal strategy towards super-elastic hydrogels. Polym. Chem. 2019, 10, 2263-2272. [CrossRef]

13. Wang, C.; Tian, L.; Zhu, W.; Wang, S.; Wang, P.; Liang, Y.; Zhang, W.; Zhao, H.; Li, G. Dye@bio-MOF-1 Composite as a Dual-Emitting Platform for Enhanced Detection of a Wide Range of Explosive Molecules. ACS Appl. Mater. Interfaces 2017, 9 , 20076-20085. [CrossRef] [PubMed]

14. Kreno, L.E.; Leong, K.; Farha, O.K.; Allendorf, M.; Van Duyne, R.P.; Hupp, J.T. Metal-Organic Framework Materials as Chemical Sensors. Chem. Rev. 2012, 112, 1105-1125. [CrossRef]

15. Rocha, J.; Carlos, L.D.; Paz, F.A.A.; Ananias, D. Luminescent multifunctional lanthanides-based metal-organic frameworks. Chem. Soc. Rev. 2011, 40, 926-940. [CrossRef] [PubMed]

16. Cao, C.; Liu, Q.; Shi, M.; Feng, W.; Li, F. Lanthanide-Doped Nanoparticles with Upconversion and Downshifting Near-Infrared Luminescence for Bioimaging. Inorg. Chem. 2019, 58, 9351-9357. [CrossRef]

17. Sun, G.; Xie, Y.; Sun, L.; Zhang, H. Lanthanide upconversion and downshifting luminescence for biomolecules detection. Nanoscale Horizons 2021, 6, 766-780. [CrossRef]

18. You, W.; Tu, D.; Zheng, W.; Shang, X.; Song, X.; Zhou, S.; Liu, Y.; Li, R.; Chen, X. Large-scale synthesis of uniform lanthanide-doped $\mathrm{NaREF}_{4}$ up-conversion/downshifting nanoprobes for bioapplications. Nanoscale 2018, 10, 11477-11484. [CrossRef] 
19. Liu, J.; Rijckaert, H.; Zeng, M.; Haustraete, K.; Laforce, B.; Vincze, L.; Van Driessche, I.; Kaczmarek, A.M.; Van Deun, R. Simultaneously Excited Downshifting/Upconversion Luminescence from Lanthanide-Doped Core/Shell Fluoride Nanoparticles for Multimode Anticounterfeiting. Adv. Funct. Mater. 2018, 28, 1707365. [CrossRef]

20. Zhu, Q.; Sun, T.; Chung, M.N.; Sun, X.; Xiao, Y.; Qiao, X.; Wang, F. Yb ${ }^{3+}$-sensitized upconversion and downshifting luminescence in $\mathrm{Nd}^{3+}$ ions through energy migration. Dalton Trans. 2018, 47, 8581-8584. [CrossRef]

21. Brites, C.D.S.; Balabhadra, S.; Carlos, L.D. Lanthanide-Based Thermometers: At the Cutting-Edge of Luminescence Thermome-try. Adv. Opt. Mater. 2018, 7, 1801239. [CrossRef]

22. Liu, J.; Wang, Q.; Sang, X.; Hu, H.; Li, S.; Zhang, D.; Liu, C.; Wang, Q.; Zhang, B.; Wang, W.; et al. Modulated Luminescence of Lanthanide Materials by Local Surface Plasmon Resonance Effect. Nanomater. 2021, 11, 1037. [CrossRef] [PubMed]

23. Zhao, H.; Zang, L.; Guo, C. Influence of lanthanide ion energy levels on luminescence of corresponding metalloporphyrins. Phys. Chem. Chem. Phys. 2017, 19, 7728-7732. [CrossRef]

24. Gao, Y.; Jing, P.; Yan, N.; Hilbers, M.; Zhang, H.; Rothenberg, G.; Tanase, S. Dual-mode humidity detection using a lanthanidebased metal-organic framework: Towards multifunctional humidity sensors. Chem. Commun. 2017, 53, 4465-4468. [CrossRef] [PubMed]

25. Stangl, J.M.; Dietrich, D.; Sedykh, A.E.; Janiak, C.; Müller-Buschbaum, K. Luminescent MOF polymer mixed matrix membranes for humidity sensing in real status analysis. J. Mater. Chem. C 2018, 6, 9248-9257. [CrossRef]

26. Gong, M.; Li, Y.; Guo, Y.; Lv, X.; Dou, X. $2 \mathrm{D} \mathrm{TiO} 2$ nanosheets for ultrasensitive humidity sensing application benefited by abundant surface oxygen vacancy defects. Sens. Actuators B Chem. 2018, 262, 350-358. [CrossRef]

27. Wang, L.L.; Wang, H.Y.; Wang, W.C.; Li, K.; Wang, X.C.; Li, X.J. Capacitive humidity sensing properties of ZnO cauliflowers grown on silicon nanoporous pillar array. Sens. Actuators B Chem. 2013, 177, 740-744. [CrossRef]

28. Zhang, Y.; Chen, Y.; Zhang, Y.; Cheng, X.; Feng, C.; Chen, L.; Zhou, J.; Ruan, S. A novel humidity sensor based on $\mathrm{NaTaO}_{3}$ nanocrystalline. Sens. Actuators B Chem. 2012, 174, 485-489. [CrossRef]

29. Luo, J.; Xu, H.; Liu, Y.; Zhao, Y.; Daemen, L.L.; Brown, C.; Timofeeva, T.V.; Ma, S.; Zhou, H.-C. Hydrogen Adsorption in a Highly Stable Porous Rare-Earth Metal-Organic Framework: Sorption Properties and Neutron Diffraction Studies. J. Am. Chem. Soc. 2008, 130, 9626-9627. [CrossRef]

30. Nakazawa, E.; Shionoya, S. Cooperative Luminescence in $\mathrm{YbPO}_{4}$. Phys. Rev. Lett. 1970, 25, 1710-1712. [CrossRef]

31. Chen, D.; Yu, Y.; Huang, P.; Weng, F.; Lin, H.; Wang, Y. Optical spectroscopy of $\mathrm{Eu}^{3+}$ and $\mathrm{Tb}^{3+}$ doped glass ceramics containing $\mathrm{LiYbF}_{4}$ nanocrystals. Appl. Phys. Lett. 2009, 94, 041909. [CrossRef]

32. de la Rosa, E.; Solis, D.; Díaz-Torres, L.A.; Salas, P.; Angeles-Chavez, C.; Meza, O. Blue-green upconversion emission in $\mathrm{ZrO}_{2}$ : $\mathrm{Yb}^{3+}$ nanocrystals. J. Appl. Phys. 2008, 104, 103508. [CrossRef]

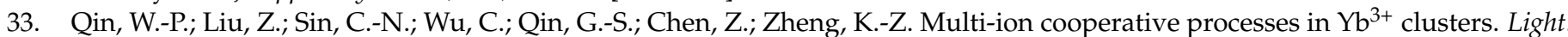
Sci. Appl. 2014, 3, e193. [CrossRef]

34. Nakazawa, E. Cooperative optical transitions of $\mathrm{Yb}^{3+}-\mathrm{Yb}^{3+}$ and $\mathrm{Gd}^{3+}-\mathrm{Yb}^{3+}$ ion pairs in $\mathrm{YbPO}_{4}$ hosts. J. Lumin. 1976, 12-13, 675-680. [CrossRef]

35. Knighton, R.C.; Soro, L.K.; Francés-Soriano, L.; Rodríguez-Rodríguez, A.; Pilet, G.; Lenertz, M.; Platas-Iglesias, C.; Hildebrandt, N.; Charbonnière, L.J. Cooperative Luminescence and Cooperative Sensitisation Upconversion of Lanthanide Complexes in Solution. Angew. Chem. Int. Ed. 2021, 61, e202113114. [CrossRef]

36. Hehlen, M.P.; Kuditcher, A.; Rand, S.C.; Lüthi, S.R. Site-Selective, Intrinsically Bistable Luminescence of $\mathrm{Yb}^{3+} \mathrm{Ion} \mathrm{Pairs} \mathrm{in} \mathrm{CsCdBr}_{3}$. Phys. Rev. Lett. 1999, 82, 3050-3053. [CrossRef] 